\title{
NEONATAL SEPSIS;
}

COMMON BACTERIAL ISOLATES AND THEIR ANTIMICROBIAL SUSCEPTIBILITY PATTERNS IN NEONATAL INTENSIVE CARE UNIT, ISLAMABAD

1. Assistant Professor Paediatrics HBS General Hospital and Medical College, Islamabad.

2. MCPS, FCPS (Med)

FCPS II (Gastroenterology), Assistant Professor,

Shaheed Zulfigar Ali Bhutto Medical University, PIMS, Islamabad.

3. FCPS Paeds,

Assistant Professor Paediatrics HBS General Hospital and Medica College, Islamabad.

Correspondence Address:

Dr. Shafat Khatoon

Assistant Professor Paediatrics

HBS General Hospital and

Medical College, Islamabad.

dr.shifa.mustafa@hotmail.com

Article received on:

06/05/2017

Accepted for publication:

$15 / 08 / 2017$

Received after proof reading: 06/10/2017

\section{Nazia Bashir Abbasi ${ }^{1}$, Nighat Jabeen ${ }^{2}$, Shafat Khatoon ${ }^{3}$}

ABSTRACT... Introduction: Neonatal sepsis is a systemic condition characterized by bacteremia that occurs in the first month of life. It is a fatal condition and need to be treated promptly. Bacterial isolates include both gram positive and negative bacteria and the cure of condition is highly dependent on antimicrobial drug sensitivity and resistant patterns. It is there for utmost important to known commonly occurring bacteria in neonatal septic states and their drug sensitivity patterns. Objectives: To determine the frequency of the bacterial isolates in blood and their sensitivity patterns to commonly used antibiotics in neonatal sepsis. Setting: Neonatal intensive care unit(NICU), Department of Shifa International Hospital. (SIH), Islamabad. Study Design: Cross sectional. Duration: This study was conducted between $61^{\text {st }}$ June 2013 to $30^{\text {th }}$ November 2013. Subject and Methods: A total of 180 neonates, admitted in NICU with evidence of clinical sepsis i.e. with signs and symptoms suggestive of septicemia (fever, lethargy, reluctance to feed, seizures, and irritability) were included in this study. The samples for blood cultures were taken. Identification of bacterial isolates was carried out by the standard bacteriological techniques, which include gram staining and bacterial cultures and antimicrobial sensitivity patterns which was performed by modified Kirby and Bauer disc diffuse method as per CLSI (Clinical and Laboratory StandardsInstitute)guidelines.A predesigned Performa was filled. Results: Culture revealed bacterial growth in $7.2 \%$ samples. Gram negative organisms were observed in $6.67 \%$ and only 1 were gram positive. In this study, $50 \%$ and $100 \%$ of E-coli were sensitive to ampicillin, meropenem and amikacin, gentamycin respectively. Sixty to $100 \%$ of pseudomonas was sensitive to ceftazidime, tazobactum, meropenem and $100 \%$ of enterococcus was sensitive to ampicillin and vancomycin. Conclusion: Antimicrobial drug resistance and constantly changing resistance patterns is emerging issues in various groups of infections and septic states, especially for routinely used antibiotics as found in our study. Thus by prescribing rational use of antimicrobial as per bactriogram, It'll be easier totreat sepsis effectively and economically and reduce the mortality and morbidity related to neonatal sepsis.

Key words: Neonatal Sepsis, Blood Culture, Gram Positive and Negative Organisms, Sensitivity Pattern.

Article Citation: Abbasi NB, Jabeen N, Khatoon S. Neonatal sepsis; common bacterial isolates and their antimicrobial susceptibility patterns in neonatal Intensive Care Unit, Islamabad. Professional Med J 2017;24(10):1455-1460.

DOI:10.17957/TPMJ/17.3914

\section{INTRODUCTION}

Septicemia is a systemic condition characterized by bacteremia and when it affects neonates in first month of life is called as neonatal sepsis. It is fatal condition and need to be treated by means of sensitive and effective antimicrobial agents. Clinical signs and symptoms of neonatal sepsis include fever, lethargy, reluctance to feed, seizures, tachypnea, tachycardia etc. ${ }^{1}$ It is mainly divided in to two groups depending on time period and peri partum pathogenesis. Early onset sepsis that occurs at any time from birth to $7^{\text {th }}$ days of lifeand late onset sepsis that occurs from day $7^{\text {th }}$ till one month of life. In developed countries the incidence of the neonatal sepsis is much less i-e 1-4 per 1000 live births because a septic deliveries and improved neonatal care ${ }^{2}$ while it'sthe leading cause of mortality and morbidity in the developing countries. ${ }^{3}$ The neonatal mortality rate ofPakistan is $49 / 1000$ live births. ${ }^{4}$

In neonatalsepsis the commonestbacterial isolates are gram positive bacterial agents in developed countries ${ }^{2}$ and according to a study conducted at 
a tertiary care hospital of Australia, staphylococcal sepsis is the most common bacterial isolate among gram positive bacteria. ${ }^{5}$ Similarly, group B Streptococcus is considered as one of the most common pathogens in the early onset sepsis ${ }^{6}$ but is relatively uncommon in countries like Pakistan. ${ }^{7}$ One of the studies conducted in Bhavnagar, India reported that the commonest isolate in neonatal sepsis wasKlebsiella and $E$. coli. Similarly antimicrobial susceptibility pattern of bacteria also varies in developed and under develop countries. ${ }^{8}$ According to an study conducted at Sheikh Zaid hospital, Lahore on 150 cases of suspected neonatal sepsis, it was found that the most common organisms detected were gram negative bacteria (86\%), which include E.coli (20\%), Klebsiella (13\%). Only 14\% were gram positive and out of which staph aureus was only $8 \%$.Most of these organisms were resistant to ampicillin, gentamycin and cefotaxime. ${ }^{9}$ Only $10 \%$ and $26 \%$ of E.coli was sensitive to ampicillin and gentamycin respectively. Sensitivity of Klebseillaand Stapaureus to gentamycin was 23\% and $25 \%$ to respectively. Sensitivity of Amikacin was $57 \%$ for E.coli, $61 \%$ forKlebseilla and $50 \%$ for Staph aureus. ${ }^{9}$ The rationale of my study is to find out the most common pathogens responsible for neonatal sepsis and their antimicrobial sensitivity patterns to various antibiotics. Knowing bacteriogram'll limit the unnecessary use of the antibiotics and the emergence of multidrug resistant organisms. It will also be helpful to review the commonly used empirical treatment regimens, judicious use of antibiotics and their cost effectiveness. This can reduce theoverall mortality and morbidity related to neonatal sepsis.

\section{Study Design}

This is a Cross sectional, observational study

\section{Study Settings}

Conducted at Shifa International Hospital, NICU Islamabad

\section{Duration of Study}

Comprised of6 months study starting from $1^{\text {st }}$ June, 2013 to 3th November, 2013

\section{Sample Size}

By using WHO sample size calculator, the sample size is collected, the values taken as Confidence level $95 \%$, anticipated population proportion $8 \%^{12}$ and absolute precision required is $4 \%$. With these values sample size calculated was 180 patients.

\section{Sample Technique}

The technique used was, Consecutive, Nonprobability

\section{Inclusion Criteria}

Study population included neonates aged 0-1 month, admitted in NICU with clinical suspicion of septicemia. (fever, lethargy, reluctance to feed, seizures, irritability etc)

\section{Exclusion Criteria}

All the neonates with congenital anomalies like dysmorphism, congenital heart disease, renal and Gastrointestinal abnormalities were excluded from study

Neonates already received antibiotics prior to admission were also excluded from study.

\section{Data Collection Procedure}

This study was conducted in $\mathrm{SIH}, \mathrm{NICU}$, Islamabad. Neonates fulfilling the above mentioned criteria were included in this study. The blood cultures were taken and sent in culture bottles to the department of Microbiology. Becton Dickinson cultures bottles was inoculated with specimen and incubated in Bactec 9240 Blood culture system. Identification of isolates was carried out by the standard bacteriological techniques, which include gram stain and culture sensitivity, which was performed by modified Kirby and Bauer disc diffuse methods according to per guidelines. Inhibition zone sizes were interpreted as per CLSI guidelines. Culture report was reported by the Department of Microbiology within 5 days. A predesigned Performa was filled by the researcher itself.

\section{Data Analysis Procedure}

The statistical analysis was performed using SPSS 16. Frequency and percentages were calculated for categorical values like gender, 
blood isolates and their sensitivity patterns. Mean and Standard deviation were calculated for the quantitative variables like age. Chi-square test was applied and $p$ value less than 0.05 consideredas significant.

\section{RESULTS}

A total of 180 neonates, admitted in NICU with evidence of clinical sepsis were included in this study. There were $121(67.22 \%)$ were male and $59(32.78 \%)$ were female as shown in Figure-1.

Out of 180 suspected sepsis, culture growth was observed in $13(7.2 \%)$ neonate and culture bacteria growth was not observed in 167(92.7\%) neonates as in figure 2. Gram negative organisms were observed in $6.67 \%(12 / 180)$, which include $2(1.1 \%)$ acinetobacter, 2(1.1\%) e.coli, 5(2.8\%) klebsiella and $3(1.6 \%)$ pseudomonas. Only 1 were gram positive that is enterococcus as presented in Figure-2 and Table-l. These organisms with respect to age of neonate were presented in Table-Il.

In this study, $50 \%$ of Acinetobacter was sensitive to amikacin, gentamycin and meropenem. 50\% and $100 \%$ of E-coli were sensitive to ampicillin, meropenem and amikacin, gentamycin respectively. Twenty percent of klebsiella was sensitive to meropenem and tazobactum. Sixty to $100 \%$ of pseudomonas was sensitive to ceftazidime, tazobactum, meropenem while $33.3 \%$ of pseudomonas was sensitive to amikacin and gentamycin. $100 \%$ of enterococcus was sensitive to ampicillin and vancomycin.

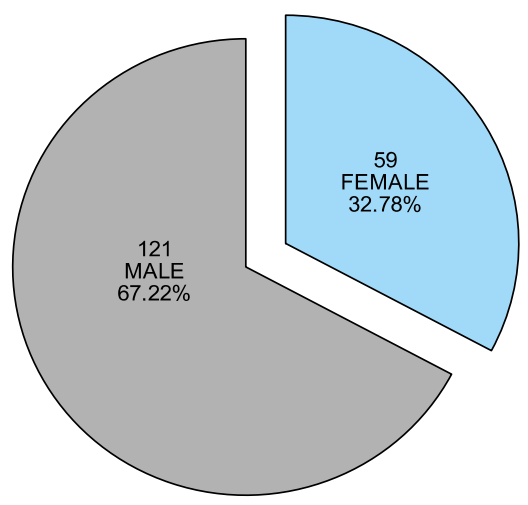

Figure-1. Sex distribution of the children $(n=180)$

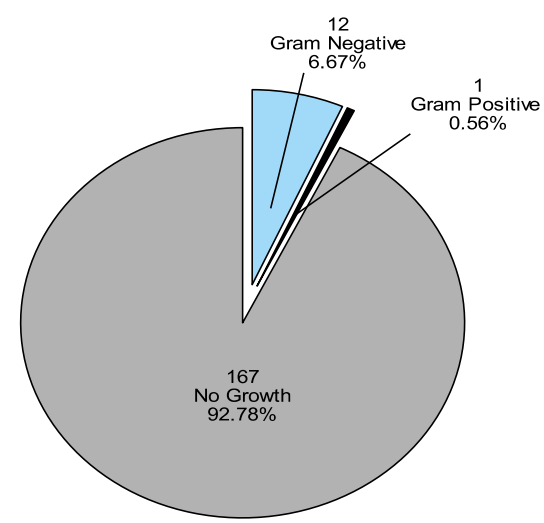

Figure-2. Micro organisms isolated $(n=180)$

\begin{tabular}{|l|c|c|c|}
\hline \multicolumn{1}{|c|}{ Organisms } & organisms & Frequency & Percentage \\
\hline Acinetobacter & Negative & 2 & $1.1 \%$ \\
\hline E.coli & Negative & 2 & $1.1 \%$ \\
\hline Klebsiella & Negative & 5 & $2.8 \%$ \\
\hline Pseudomonas & Negative & 3 & $1.6 \%$ \\
\hline Enterococcus & Positive & 1 & $0.56 \%$ \\
\hline No Growth & \multicolumn{3}{|c|}{\begin{tabular}{c}
$92.8 \%$ \\
\hline \multicolumn{2}{|c|}{ Table-l. Frequency of the bacterial isolates in blood } \\
$(n=180)$
\end{tabular}} \\
\hline
\end{tabular}

\begin{tabular}{|l|c|c|}
\hline \multirow{2}{*}{ Organisms } & \multicolumn{2}{c|}{ Age Groups } \\
\hline Acinetobacter & $\mathbf{1}$ to $\mathbf{1 5}$ days & $\mathbf{1 6}$ to $\mathbf{3 0}$ days \\
\hline E.coli & $2(1.3 \%)$ & $0(0 \%)$ \\
\hline Klebsiella & $2(1.3 \%)$ & $0(0 \%)$ \\
\hline Pseudomonas & $3(2 \%)$ & $2(6.9 \%)$ \\
\hline Enterococcus & $3(2 \%)$ & $0(0 \%)$ \\
\hline No Growth & $1(1.3 \%)$ & $0(0 \%)$ \\
\hline Table-Il. Distribution of bacterial isolates according to \\
age of neonates
\end{tabular}

\section{DISCUSSION}

Neonatal sepsis is a common health problem especially in developed countries. Poor socio economic factors, illiteracy, lack of health education, poor maternal health, poor compliance to antenatal visits and non-professional handling of deliveries all these factors are directly or indirectly related to increased rate of neonatal infection rate. According to a consensus 75-90\% of Spontaneous Vaginal deliveries are being carried out homes by a relatively untrained birth attendant in developed countries. ${ }^{10}$ 


\begin{tabular}{|l|c|c|c|c|c|}
\hline Sensitivity Pattern & $\begin{array}{c}\text { Acinetobacter } \\
\mathbf{n = 2}\end{array}$ & $\begin{array}{c}\text { E.coli } \\
\mathbf{n = 2}\end{array}$ & $\begin{array}{c}\text { Klebsiella } \\
\mathbf{n = 5}\end{array}$ & $\begin{array}{c}\text { Pseudomonas } \\
\mathbf{n = 3}\end{array}$ & $\begin{array}{c}\text { Enterococcus } \\
\mathbf{n = 1}\end{array}$ \\
\hline Ampicillin & $0(0 \%)$ & $1(50 \%)$ & $0(0 \%)$ & $0(0 \%)$ & $1(100 \%)$ \\
\hline Amikacin & $1(50 \%)$ & $2(100 \%)$ & $0(0 \%)$ & $1(33.3 \%)$ & $0(0 \%)$ \\
\hline Gentamycin & $1(50 \%)$ & $2(100 \%)$ & $0(0 \%)$ & $1(33.3 \%)$ & $0(0 \%)$ \\
\hline Cefotaxime & $0(0 \%)$ & $0(0 \%)$ & $0(0 \%)$ & $0(0 \%)$ & $0(0 \%)$ \\
\hline Ceftazidime & $0(0 \%)$ & $0(0 \%)$ & $0(0 \%)$ & $2(66.6 \%)$ & $0(0 \%)$ \\
\hline Cloxacillin & $0(0 \%)$ & $0(0 \%)$ & $0(0 \%)$ & $0(0 \%)$ & $0(0 \%)$ \\
\hline Meropenem & $1(50 \%)$ & $1(50 \%)$ & $1(20 \%)$ & $3(100 \%)$ & $0(0 \%)$ \\
\hline Tazobactum & $0(0 \%)$ & $0(0 \%)$ & $1(20 \%)$ & $2(66.6 \%)$ & $0(0 \%)$ \\
\hline Vancomycin & $0(0 \%)$ & $0(0 \%)$ & $0(0 \%)$ & $0(0 \%)$ & $1(100 \%)$ \\
\hline
\end{tabular}

Table-III. Frequency of the bacterial isolates in blood and their sensitivity to commonly used antimicrobials

In developed countries situations much better due to relatively better socioeconomic factors, education and health awareness status, properly trained health attendants (Obstetrician and pediatrician), a septic handling and better neonatal health. Factors which contribute to neonatal sepsis include premature deliveries, premature rupture of membranes, septic handling of delivery, frequent manipulation of the baby with un hygienic means etc. As per data from India $50-60 \%$ of neonatal sepsis occur in premature babies and low birth weight. ${ }^{11}$ These scenarios are changing with progressive improvement in health care facilities, provision of more potent broad spectrum antibiotics and improved knowledge about microorganisms susceptibility patterns, that's why in developed countries the rates of perinatal infection has declined from $50-60 \%$ that was twenty years ago to $20-30 \% .^{12}$

The commonest gram negative organisms involved in neonatal sepsis are Klebsiella, E coli, pseudomonas and salmonella while the commonest gram positive organisms isolated arestaphylococcusaurous, coagulase negative staphylococci (CONS), pneumococcus and step to coccuspyogenes. Drug sensitivity patterns shows that $5-50 \%$ staphylococcus including coagulase negative \& streptococcus have developed resistance against third generation cephalosporin. ${ }^{13,14}$

In our study gram negative organism was observed in $6.67 \%(12 / 180)$, which include $2(1.1 \%)$ acinetobacter, 2(1.1\%) E.coli, 5(2.8\%) klebsiella and $3(1.6 \%)$ pseudomonas. Only 1 were gram positive that is enterococcus. An observational study conducted at Sheikh Zayed hospital, Lahore reported that out of 150 cases of suspected sepsis, most common were gram negative (86\%), which include E.coli (20\%), Klebsiella (13\%). Only $14 \%$ were gram positive and out of which staphy aureus is only $8 \%$. Most of the organisms were resistant to ampicillin, gentacin and cefotaxime. ${ }^{9}$

The frequency of bacterial isolates in Khan et al study was as $^{15}$, Escherichia coli in 36(40.91\%) cases, Klebsiella spp. in $17(19.32 \%)$ cases, Staphylococcus aureus in $14(15.91 \%)$ cases, Pseudomonas aeruginosa in12(13.63\%) cases and Staphylococcus epidermidis in 9(10.23\%) cases.

In our study, $50 \%$ of Acinetobacter was sensitive to amikacin, gentamycin and meropenem. 50\% and $100 \%$ of E-coli were sensitive to ampicillin, meropenem and amikacin, gentamycin respectively. Twenty percent of klebsiella was sensitive to meropenem and tazobactum. Sixty to $100 \%$ of pseudomonas was sensitive to ceftazidime, tazobactum, meropenem while $33.3 \%$ of pseudomonas was sensitive to amikacin and gentamycin. $100 \%$ of enterococcus was sensitive to ampicillin and vancomycin. In Ahmad et al study only $10 \%$ and $26 \%$ of E.coli was sensitive to ampicillin and gentamycin respectively. Similarly isolated Klebseilla was $23 \%$ sensitive to gentamycin, while sensitivity of Staph aureus was $25 \%$ to gentamycin. Amikacin sensitivity was $57 \%, 61 \%$ and $50 \%$ for E. coli, Klebseilla and Staph aureus respectively. ${ }^{9}$ 
Antimicrobial sensitivity patterns are given in Waheed et al study. ${ }^{16}$ according to that study cefotaxime was the most effective drug and covers most of bacterias as; $80 \%$ to Klebsiella, $70 \%$ staphylococcus aureus and $65 \%$ Escherichia coli. Ceftazidime showed similar effectiveness. $80 \%$ klebsilla was sensitive to Amikacin but it was less sensitive for other organisms. No encouraging or impressiveresults were shown for ciprofloxacin sensitivity. In another study i-e Anwar et $\mathrm{al}^{17}$ amikacin was found as the most effective antibacterial agent and it had 90$100 \%$ effectiveness, cefotaxime was the second most effective agent with sensitivity of $84-89 \%$ and sensitivity to Ampicillin was less than $20 \%$. An other study Ellabib et al revealed that the most common bacterial isolate in neonatal sepsis was Enterobacteriaceae, (Serratia, Klebsiella and Enterobacter spp.) others were staphylococci both coagulase negative and positive. Antimicrobial sensitivity patterns showed imipenem, ciprofloxacin and piperacillin/ tazobactam as effective agents while almost allthe staphylococci were sensitive to vancomycin. ${ }^{18}$

One of study from Bangladeshi showed that the most common bacterial isolate in neonatal sepsis was Ecoli (30\%) while in Indian study the most common isolate was klebsiella (55\%). ${ }^{12}$ Antimicrobial sensitive patterns for those bacteria was imipenem, ciprofloxacin, gentamycin and cotrimoxazole. Imipenem was relatively costlymedicine andinadequate safety data was present for ciprofloxacin. Because of frequent and sometimes irrational use of antibiotics, bacterias are showing resistance patterns to previously sensitive antibiotics. These patterns are different in different places and its constantly changing. ${ }^{19}$ it is there for necessary to identify common bacterial isolates and their common sensitivity patterns so that judicious use of antibiotics can be ensured to attain maximum response rate and thus cure of infection.

\section{CONCLUSION}

A gram negative organism was observed the most common pathogens locally and its sensitivity, limit the unnecessary use of the antibiotics and the emergence of multidrug resistant organisms.
Drug resistance is an import hindrance in infections management especially for routinely used antibiotics as found in our study. By knowing the common bacterial isolates and their drug sensitivity patterns it would be possible to cure neonatal sepsismore effectively.

\section{Recommendations}

Every Hospital should arrange studies to find bacteriogram to determine common bacterial isolates in their locality and their Antimicrobial sensitivity patterns in order to designed better and effective empirical treatment (Antimicrobial) regimens, avoid unnecessary use of antibiotics and emergence of drug resistance. In this way sepsis related mortality and mortality can be reduced and treatment can be made relatively cost effective.

\section{Copyright@ 15 Aug, 2017.}

\section{REFERENCE}

1. Gomella T. L. Diseases and disorders (665). Neonatology. $6^{\text {th }}$ Edition.USA: McGraw Hill; 2009.

2. Stoll BJ. Nelson Textbook of Pediatrics. $19^{\text {th }}$ Edition. Philadelphia: Suanders; 2011.

3. Jehan I, Harris H, Salat S, Zeb A, Mobeen N, Pasha O, et al. Neonatal mortality, risk factors and causes; a prospective population based cohort study in urban Pakistan. Bulleitin of the World Health Organization. 2009; 87:130-38.

4. Gwee A, Coghlan B, Everett D, Chagoma N, Phiri A, Wilson $\mathrm{L}$, et al. Bacteraemia in Malawian neonates and young infants 2002-2007: a retrospective audit. BMJ Open. 2012; 2(3).e000906.

5. Weston EJ, Pondo T, Lewis MM, Martell P, Morin C, Jewell B, et al. The burden of invasive early-onset neonatal sepsis in the United States, 2005-2008. Pediatr Infect Dis J. 2011; 30(11): 937-41.

6. Zaidi AK, Thaver D, Ali SA, Khan TA. Pathogens associated with sepsis in newborns and young infants in developing countries. Pediatr Infect Dis J. 2009; 28: S10-8.

7. Kayange N, Kamugisha E, Mwizamholya DL, Jeremiah S, Mshana SE. Predictors of positive blood culture and deaths among neonates with suspected neonatal sepsis in a tertiary hospital, Mwanza-Tanzania. BMC Pediatr. 2010; 10:39-43.

8. Sivanandan S, Soraisham AS, Swarnam K. Choice and 
duration of antimicrobialtherapy for neonatal sepsis and meningitis. Int J Pediatr. 2011; 2011:7121-50

9. Ahmad A, Hussain W, Lamichhane A, Aslam M, Riaz L. Use of Antibiotics in Neonatal Sepsis at Neonatal Unit of A Tertiary Care Hospital. Pak Paed J. 2011; 35(1): 3-7.

10. Begg SA, Cransweek NE, Reed MD. Improving drug use for children of the developing world. Arch Dis Child. 2005; 90:1091-3.

11. Bang AJ, Bang RA, Baitale B. Burden of morbidities and unmet need for healthcare in rural Indian neonate. IndPediatr. 2001; 38:952-65.

12. Ahmed ASMNU, Chowdhury MAKA, Hoque M, Damstadt GL. Clinical \& Bacteriological profile of neonatal septicemia in tertiary level pediatric hospital in Bangladesh. IndPediatr. 2002; 39:1034-9.

13. Vernango $S$, Sharland $M$, Kazembe $P$, Mwansambo $C$, Heath PT. Neonatal sepsis: An international perspective. Arch Dis Child Fetal Neonatal. 2005; 90:F220-4.
14. Gandy G. Reunie J. Antibiotic treatment for suspected neonatal meningitis. Arch Dis Child. 1990; 65:1-2.

15. Khan MA, Khan A, Shah F, Munir A. Neonatal sepsis: a study of causative pathogens and their antimicrobial sensitivity pattern at tertiary hospital. Gomal J Med Sci. 2012; 10: 244-7.

16. Waheed M, Laeeq A, Maqbool S. The etiology of neonatal sepsis and patterns of antibiotic resistance. $J$ Coll Physicians Surg Pak. 2003; 13:449-52.

17. Anwer SK, Mustafa S, Priyani S, Ashraf S, Taufiq KM. Neonatal sepsis, and etiological study. J Pak Med Assoc. 2000 ; 50: 91-4.

18. Ellabib MS, Ordonez A, Ramali A, Walli A, Benayad T, Shebrlo $\mathrm{H}$. Changing pattern of neonatal bacteremia. Microbiology and antibiotic resistance. Saudi Med J. 2004; 25:1951-6.

19. Deman $P$, Verhoeven BA, Verburgh HA. An antibiotic policy to prevent emergence of resistance bacilli. Lancet. 2000; 355:973-8.

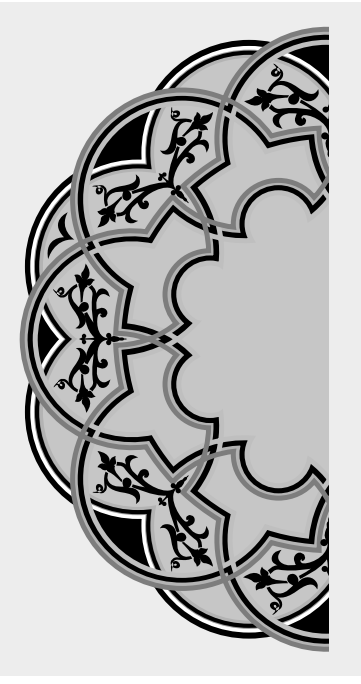

\title{
“Don't hate what you don't understand."
}

\author{
Unknown
}

\section{AUTHORSHIP AND CONTRIBUTION DECLARATION}

\begin{tabular}{|c|l|}
\hline Sr. \# & Author-s Full Name \\
1 & Nazia Bashir Abbasi \\
2 & Nighat Jabeen \\
3 & Shafat Khatoon \\
\hline
\end{tabular}

\author{
Contribution to the paper \\ Concept, Study design, Data \\ collection \\ Concept, and data analysis \\ Intellectual concept, Study \\ design, Analysis, Discussion
}

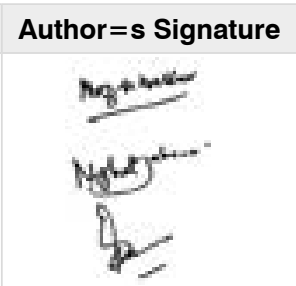

